\title{
A mística e a mecânica em filosofia moral
}

\author{
Mystic and mechanics in moral philosophy
}

DOI: https://doi.org/10.20873/rpv6n1-94

\section{João Batista Magalhães Prates}

Orcid ID: https://orcid.org/0000-0001-9777-6427

Email: batistaprates1@gmail.com

\section{Resumo}

Em Intertexto, poema de B. Brecht ${ }^{1}$, uma questão filosófica é tratada: por que devo preocupar-me com os outros? A alusão ao poema insere-nos de pronto no vértice desse trabalho. Trata-se do problema da alteridade. Percorreremos as abordagens clássicas da ética autocentrada, situando em cada uma delas um vício original, a saber, a confusão entre tempo e espaço. Fora dos marcos da metafísica bergsoniana, deixa-se de considerar uma dimensão da realidade, o tempo. 0 resultado será a constituição de uma ética coadunada com a natureza das representações intelectuais - espaciais, portanto -, estruturada pela lógica da conservação, o que sacrificará necessariamente o alcance da universalidade, compreendida em seu sentido largo, a qual não será jamais, sob a perspectiva bergsoniana, alcançada sem o contato com o que há de mais íntimo no real, o tempo, o movimento criador. 0 caráter autorreferenciado da tradição ética aparecerá como desdobramento de um modo de vida (fechado) que orienta a confecção e interpretação da forma legal, atingido pela manifestação normal de nossas faculdades para estar e agir no mundo.

\section{Palavras-chave}

Bergsonismo. Ética. Direitos animais.

\begin{abstract}
In a Brecht's poem a philosophical question in posed: why should I care about others? The poem projects us in the core of this paper, about the "problem of alterity". We intend to pass through the classical self-centered approaches in moral philosophy, discerning in each one of them a main misperception: the correspondence between time and space, that results in a intellectualized ethics, guided by special representation, structured
\end{abstract}

\footnotetext{
${ }^{1}$ Primeiro levaram os negros / Mas não me importei com isso / Eu não era negro / Em seguida levaram alguns operários / Mas não me importei com isso / Eu também não era operário / Depois prenderam os miseráveis / Mas não me importei com isso / Porque eu não sou miserável / Depois agarraram uns desempregados / Mas como tenho meu emprego / Também não me importei /Agora estão me levando / Mas já é tarde. /Como eu não me importei com ninguém / Ninguém se importa comigo.
} 
by the logic of conservation. This approach necessarily put down the intuition of broad universality, wich, according to Bergson, can't be reached without the intuition of real time, the creative movement of reality. This self-centered aspect of classical ethics appears, for Bergson, as a development of a closed way of living, the one that orientates the form of the law and is archived by the usual manifestation of our spatial faculties of intelligence.

\section{Keywords}

Bergsonism. Ethics. Animal rights.

\section{Introdução}

Em As Duas Fontes da Moral e da Religião, Bergson trata de aplicar todo o edifício teórico construído anteriormente aos problemas da moral e da política. Os conceitos chave cunhados pelo autor como fechado e aberto; imobilismo e movimento; diferenciação e coincidência; individuação e comunhão são cruciais para compreender os confrontos e impasses da contemporaneidade no que diz respeito ao alargamento da esfera moral e jurídica, seja para que novos direitos sejam reconhecidos a novos ou velhos sujeitos de direito, seja para que velhos direitos já reconhecidos passem ater eficácia, realizando a possibilidade de aperfeiçoamento do humano - na medida em que permite nossa natureza.

No decurso da obra bergsoniana, entre outros propósitos do filósofo, encontramos o intuito de mover o eixo interpretativo do Ser, que esteve assentado no lado da matéria desde a guinada cientificista, para o lado do espírito, realidade que seu pensamento se dispõe a desvendar e fundamentar positivamente. Ainda que o espírito, nesse caso, notemos desde já, não possa ser pensado fora de sua relação com a materialidade, como compreendemos ao percorrer o conjunto dos seus textos. De todo modo, o espiritualismo bergsoniano opõe-se ao puro intelectualismo, uma vez que permite saltar para fora das perspectivas da razão, sempre exteriores a tudo o que vislumbra, e coincidir com pontos de vista outros a partir de seu interior ${ }^{2}$. No que tange à esfera do direito, descobrir o tempo subjacente ao espaço, com o qual esteve confundido

${ }^{2}$ Cf. LAPOLUJADE, D. Potências do Tempo, p. 95 
até então, significará, de uma perspectiva moral, a possibilidade de evadirmo-nos de nosso invólucro individual - que é ao mesmo tempo social -, para coincidirmos com o outro - um outro ponto de vista - em uma experiência profunda. Notadamente, se o outro é primeiramente apreendido em nossa profundidade, quando coincidimos com o movente em nós, é essa experiência que nos subsidia para apreensão de realidades outras ${ }^{3}$. Movimento que não se dá sem um salto para além da inteligência, para a vivência de uma emoção originária e que permitirá a compreensão de alteridades, a princípio, não sujeitas à forma tradicional do Direito e que vêm mesmo desafiá-la, visto que a nova ética a respaldar o direito se ligará antes a uma experiência intuitiva e não apenas ao trabalho da representação intelectual, nos marcos do bergsonismo.

Notadamente, essa categoria abstrata, a "alteridade" digna de consideração, pode ser preenchida com diversos conteúdos particulares. Nesse sentido, argumentaremos que a tendência a alargar o conteúdo naturalmente capaz de caber nessa mesma forma linguística depende de uma operação singular, a mesma que elide a mera operação linguística e se conforma em experiência verdadeira de alteridade, um genuíno interesse pelo bem-estar desse "outro", sempre a definir. Esse alargamento verdadeiro é justamente o que encontraremos na reflexão bergsoniana sobre a moral e que se ausenta nas teorias tradicionais da moral. Com efeito, Bergson escolhe a concepção tradicional do evolucionismo social como adversário conceitual, justamente pela impossibilidade que demonstraria, quando pesquisando a moralidade, de reconhecer essa operação a partir dos marcos espaciais de que parte. Aqui supomos que ao liberalismo - e aos seus desdobramentos que, sob determinadas perspectivas, conduzem também a uma ampliação dos direitos ${ }^{4}$ - poderíamos estender a mesma crítica, encontrando ali os mesmos equívocos identificados com o evolucionismo social e os mesmos empecilhos que surgem em suas lucubrações morais. Assim, antes de apresentarmos os quadros gerais do bergsonismo no tocante ao problema da alteridade, procuremos evidenciar algumas tendências opostas ao registro teórico que pretendemos priorizar.

\footnotetext{
3 Idem, p. 96

${ }^{4}$ Ver LEFORT, 1990 e 1983.
} 


\section{Moralidade mecânica}

Tomemos o utilitarismo, por exemplo. Essa corrente postula que o mínimo necessário para que um ser possa ser sujeito de interesses e, portanto, de direitos, é a capacidade de sentir $^{5}$. Se a inteligência, examinando o objeto a conhecer por fora, digamos, mapeando a sua superfície, pode chegar a esse critério para a moral, descrevendo o que se passa sempre que um homem reivindica a apreciação de direitos para um “outro” ou para si mesmo, ela só avançará ao ponto de recomendar a solidariedade se supor que o princípio da utilidade deve ser estendido a todas as criaturas que sentem, independente da raça, da religião, da espécie, do grupo a que pertencem. Mas só o princípio da utilidade não bastará nem para justificar essa afirmação, nem para originar a ação, uma vez que toma o indivíduo e não a alteridade por ponto de partida, prendendo-se ao si mesmo. A despeito de todas as mediações que a razão possa intercalar em prol dessa abordagem, resta o fato de que, em muitos casos, não há interesse imediato em reconhecer direitos alheios, sobretudo de minorias, pelo fato mesmo de serem minorias e não oferecerem qualquer perigo que, interessando ao sujeito diretamente, o faça defender tais direitos por um desvio autorreferenciado. 0 utilitarista ver-se-á obrigado, pois, a recorrer a um outro princípio, a saber, o "princípio da igual consideração de interesses" para explicar a operação, e aqui trairá o princípio da utilidade ao fundamentar a igualdade na inteligência pura, dessa vez em absoluto (e não em relação a um princípio outro ao qual responda). Teremos dois princípios absolutos, portanto: utilidade e igualdade. Bentham, entretanto, é categórico ao afirmar que o único princípio absoluto possível, ao qual todos os demais remetem, é o da utilidade . O desafio é explicar por que é que há obrigação moral em considerar igualmente os interesses dos outros homens quando é duvidoso que tal ato venha a contribuir com os interesses privados do agente. Nesse sentido, o liberalismo não parece ser outra coisa senão a volta que o utilitarismo faz sobre si mesmo, ora reduzindo, ora aplicando-se sobre uma metafísica dogmática, sempre que quer estender o princípio da utilidade para além da esfera do indivíduo particular,

\footnotetext{
${ }^{5}$ Cf. BENTHAM, 1984, capítulo 17.

${ }^{6}$ Cf. BENTHAM, 1984, pg. 3.
} 
distando-se dele para abraçar o outro. Ao tender para a estrita observação empírica nos assuntos morais, descobrindo a pretensa fonte única que motiva toda e qualquer ação humana - o princípio da utilidade-, ficamos tentados a estabelecer a regra que define a natureza humana da observação regular do egoísmo humano (e descambar em um hobbesianismo). Afinal, é bem fácil evocar pela memória ocasiões em que presenciamos o homem agir como lobo do homem, para falar como Hobbes, considerando apenas os seus interesses em detrimento dos interesses alheios. Nos textos de Freud abundarão relatos deste tipo. Para evadirmo-nos do paradoxo individualista que a utilidade sugere teremos que postular algum princípio como o imperativo categórico de Kant, e demonstrar que a utilidade em questão é antes de tudo utilidade social, e só indiretamente utilidade individual; que a solidariedade nos é mais útil, mesmo de uma perspectiva individual, do que o egoísmo, uma vez que melhor nos auxilia a satisfazermos nossos próprios interesses, a longo prazo. Para fundamentar tal princípio bastará talvez dizer ao hesitante que "é em seu próprio interesse que deve considerar os interesses alheios"; mas essa advertência não basta para iniciar a ação solidária, na qual o outro assume a estatura de sujeito de direitos. Em suma, a dificuldade liberal consiste em explicar como pode o interesse público estar implicado na preocupação natural com o interesse privado; como podem homens egoístas virem a se considerar como iguais - explicar inclusive se tal coisa é possível e mesmo desejável.

O propósito desse breve percurso consiste em evidenciar que qualquer leitura da moral ligada às teorias modernas partilharia de um vício original, apontado ao longo de toda a obra bergsoniana, a saber, a confusão entre tempo e espaço. Nesse sentido, arriscaríamos afirmar que fora do marco da metafísica bergsoniana, deixa-se de considerar uma dimensão da realidade, o tempo - ou se o faz de maneira equivocada, a partir das categorias estáticas da inteligência - sem o que não podemos entender como se faz a passagem do individualismo à igualdade real, por intermédio de uma "indiferença positiva", ou de um "princípio de igual consideração de interesses". Na verdade, sem esse ponto de partida, sequer podemos entender como podem existir tais coisas, uma vez que aos olhos da inteligência não existe movimento nem continuidade; não existe tempo e, portanto, não existe criação, tão somente conservação; não existe totalidade, apenas parcialidade, segundo Bergson. A humanidade, a comunhão entre 
seres sencientes, é ofuscada pela individualidade que ela recorta do todo da vida. Sob a égide da inteligência que se move no espaço tudo o que se prioriza é estático; perde-se totalmente a criação que é o movimento constitutivo da vida, o qual é fundamentalmente temporal ${ }^{7}$. Perdese, enfim, a percepção de qualquer interesse profundo, que não diga respeito ao eu superficial e à sua conexão egoísta com o social, conexão esta regulada pelos hábitos adquiridos da sociedade, graças aos quais a conservação da espécie é garantida ${ }^{8}$. Não se vislumbra jamais a universalidade no seu sentido mais radical. 0 utilitarismo só conhecerá assim o homem em sua dimensão material a qual, restrita aos contornos espaciais, constitui o indivíduo regido pelos critérios de uma ordem fechada ${ }^{9}$. Decerto, ao se mudar o enfoque do indivíduo para a sociedade, começa-se a perceber valores solidários e laços de comunhão entre o que se supunha fechado, mas confusamente continua-se a raciocinar como se a associação humana fosse efeito de uma reta razão (contratual?) a orientar a vontade individual de todos apoiada em um princípio que cabe desvendar (a utilidade?). Munidos de uma metafísica assim carente de positividade, de um entendimento parcial da realidade, sob o qual o pensamento não se evade dos quadros espaciais em que a realidade humana é representada, o salto para um efetivo universalismo, que fosse inclusive além do homem, não se verifica. Nesse sentido, o autorreferenciamento nos aparece como desdobramento natural de um modo de vida moral, que orienta a interpretação da forma legal, atingido pela manifestação normal, anterior à crítica, de nosso estar no mundo prático.

Recapitulemos os três movimentos que, interiores à obra de Bergson, nos descortinam sua ética metafísica, na tentativa de sistematizar a moral tal como compreendida sob o bergsonismo, dando a entender o que chamamos aqui de "ética ontológica", sustentada no interior de

\footnotetext{
${ }^{7}$ Cf. A percepção da mudança em BERGSON, 2006.

${ }^{8}$ Segundo o autor, a natureza nos fornece a título de instinto social a obrigação de construir hábitos, pelos quais fundamos uma regularidade e dotamos as ações humanas, livres, de um caráter de repetição necessário à regulação da vida em conjunto. Cabe a nós, entretanto, dotar a forma de conteúdo. Cf. BERGSON, 1979, pg. 19.

${ }^{9}$ Ao longo de $A$ Evolução Criadora o autor é categórico em afirmar que o indivíduo é o corpo fechado por excelência e que seria natural à inteligência espacial proceder à especulação sobre a vida tomando-o por elemento fundamental; não obstante, mostrará o autor, há sempre algo de arenoso em toda definição de indivíduo, de forma que o fechamento absoluto é mais uma ideia do que uma realidade de fato, ideia sedutora às nossas faculdades afeitas ao imobilismo, incapazes de captar a continuidade entre as coisas.
} 
um sistema metafísico ${ }^{10}$. Destacaremos o caráter abstrato da separação entre as duas tendências, a saber, o fechado e o aberto, para depois voltar a juntá-las e reconhecê-las atuantes em conjunto na realidade prática; no misto do qual partimos na nossa experiência diária. Nesse misto que fará sentido dizer de uma lei e um Direito que estejam entre as duas tendências, bem como do potencial transformador de todas as instituições humanas. Feito isso, recuperaremos o conceito de "teoria do verniz", discutido por Lefebvre, o qual enfatiza a dimensão individualista que tal abordagem teórica da moral encerra. Partindo da discussão sobre o conceito da teoria do verniz, - ao qual podemos reduzir boa parte das teorias liberais sobre moralidade -, seremos conduzidos à crítica ao liberalismo político de um ponto de vista bergsoniano. Tratase aqui de destacarmos as limitações do direito liberal em seus matizes vários, no que concerne a um verdadeiro alcance da ideia de universalidade e da inclusão da alteridade, perscrutando os erros em que essas teorias se assentam ao erigirem diferentes formulações da moralidade que encontram sua fonte exclusiva na razão humana, erro procedente de uma incompreensão da natureza humana, como evidenciará a incursão nos textos bergsonianos.

\section{Moralidade mística}

Coloquemo-nos sob uma outra perspectiva, a bergsoniana, e descobriremos a realidade do tempo enquanto ser concreto que participa da realidade na condição de força espiritual. A coincidência com essa temporalidade - a realidade movente, a duração -, que constitui a natureza última de todo o real, permitirá um salto para fora dos quadros em que se move a inteligência com sua vocação espacial e utilitária, bem como um mergulho no interior de outras perspectivas que contraditam aquelas cristalizadas pela lógica espacializada. Uma experiência de alteridade jamais sonhada pela inteligência humana, eis o possível que assim se descortinará. Ou seja, o encontro desse estofo do real - que é espiritual - permitirá um simpatizar com o real - inclusive material - para além das formas intelectualmente representadas, e portanto a apreensão de naturezas e existências a princípio destituídas de lógica e sentido. Cabe apontar

\footnotetext{
${ }^{10}$ Cf. LANDIM, 2001, pg. 198.
} 
brevemente os termos dessa experiência e suas consequências para a moral, conforme o bergsonismo.

Já no Ensaio Sobre os Dados Imediatos da Consciência, sua obra inaugural, o autor aborda o problema da liberdade humana, colocado em xeque pelo mecanicismo. Bergson sugere que o ato livre tal como pensado nesse registro se constrói como um pseudoproblema, o qual se resolve ao desvendarmos a realidade do tempo, até então confundido com o espaço. Nessa linha argumentativa irá diferenciar dois aspectos da realidade: extensão e duração. A extensão ligada ao universo da representação; a duração como o tempo da existência, o movente em nós:

Todo o determinismo (...) [se baseia] numa concepção inexacta da multiplicidade dos estados de consciência e, sobretudo, da duração. Assim (...)o princípio da conservação de energia [é invocado] sem nos interrogarmos se este princípio é igualmente aplicável aos momentos do mundo exterior, que se equivalem, e aos momentos de um ser vivo e consciente ao mesmo tempo, que mutuamente se engrandecem. De qualquer maneira, numa palavra, se se considera a liberdade, só a negamos na condição de identificarmos o tempo com o espaço. (BERGSON, 2008, pg. 100, 101 e 158)

Esse desvendamento da realidade do tempo será levado adiante em Matéria e Memória, quando o autor identifica a substância temporal com a consciência, tal qual se manifesta nos seres humanos, em seu caráter psicológico de engrandecimento através de uma memória que armazena o passado para criar um futuro indeterminado, mas também em sua dimensão ontológica. Bergson concluirá pela realidade do espírito a partir da constatação de que o conteúdo da nossa memória (como de todos os nossos estados de consciência) não é o correlato perfeito da matéria cerebral, não se reduzindo a ela (como supunha o paralelismo psicofísico).

Todos os fatos e todas as analogias estão a favor de uma teoria que veria no cérebro apenas um intermediário entre as sensações e os movimentos, que faria desse conjunto de sensações e movimentos a ponta extrema da vida mental, ponta incessantemente inserida no tecido dos acontecimentos, e que, atribuindo assim ao corpo a única função de orientar a memória para o real e de ligá-la ao presente, consideraria essa própria memória como absolutamente independente da matéria. (BERGSON, 1999, pg. 208)

As análises do funcionamento da nossa consciência (o tempo em nós) iniciam-se no Ensaio quando da abordagem dos problemas da intensidade e da linguagem. E são levadas adiante em Matéria e Memória quando da descrição dos mecanismos pelos quais armazenamos o 
passado no presente para "prestarmos atenção na vida" e podermos agir no mundo enquanto seres criadores que projetam e perseguem a novidade do futuro, porque constituídos não apenas por uma memória psicológica, mas também ontológica. Em A Evolução Criadora essa investigação prossegue; aqui o autor sintetizará o percurso anterior, passando a entender a constituição humana sob a ótica de um evolucionismo distinto do darwinista. 0 tempo, enquanto duração, antes circunscrito à dimensão mais profunda da consciência humana, será estendido ao resto da criação e se desvendará Impulso vital universal, substância que, como a consciência, progride e dura, compondo com a matéria os dois termos irredutíveis da vida, vida esta que explode enquanto criação instaurando assim as diferenças entre os seres nas suas diversas linhas evolutivas, entre as quais a mais bem sucedida levará ao homem.

Do nosso ponto de vista, a vida aparece globalmente como uma onda imensa que se propaga a partir de um centro e que, na quase totalidade de sua circunferência, detém-se e se converte em oscilação no mesmo lugar: num só ponto o obstáculo foi forçado e a impulsão passou livremente. Essa liberdade é que assinala a força da humanidade (...) o homem continua, pois, infinitamente o movimento vital, embora não arraste consigo tudo o que a vida trazia nela (...) na humanidade de que fazemos parte, a intuição acha-se quase totalmente sacrificada à inteligência (...) está presente, entretanto, embora vaga e sobretudo descontínua (...) se reascende, em suma, toda vez que um interesse vital está em jogo. (BERGSON, 1979, pg. 233-4)

Só do alto desse edifício poderemos adentrar no último livro. Aqui o autor tratará de estudar o homem enquanto ser social criador de instituições e formas de sociabilidade, após ter perscrutado o instinto social que o prende à sociedade, tornando-a viável. 0 impulso criador, essencialmente temporal, que se inscreve no ser humano e permite a ele dar continuidade ao momento vital, aparece em confronto com a sua tendência oposta, espacial e reprodutora. Não teria sido para facilitar a sobrevivência que a força espiritual teria forçado a transmutação da matéria dos seres em diversas espécies, até atingir a humana, mas para prosseguir com a vocação expansiva própria de sua natureza impulsiva e criadora. Em todas as espécies, como evidencia Bergson, esse movimento de expansão é interceptado pelos obstáculos impostos pela matéria. E mesmo aquela mais bem sucedida viverá o drama da tensão entre a inércia e o avanço contínuo, entre submergir e adormecer na repetição e no imobilismo - caracteres típicos da tendência espacial - ou assumir a intuição movente e realizar o progresso. Nessa senda, 
o último livro do autor, As duas fontes da moral e da religião, nos apresenta a escolha entre dois modos de viver a moralidade: de um lado aquela que visa "apenas sobreviver", equilibrando coletivamente os egoísmos individuais; do outro, aquela que pretende realizar o esforço - que de resto só é possível aos membros da espécie humana -, pelo qual nos elevaríamos acima da própria condição de espécie. Notadamente, ao permanecer no âmbito da estabilidade, o homem não se distinguiria muito dos outros seres vivos, prosseguindo em sua existência quase que como um mecanismo, respondendo às necessidades vitais, tal qual um computador que funcionasse sob o binarismo dor/prazer, ainda extremamente complexificado pela abertura característica da faculdade intelectiva. No segundo caso, nos assumiríamos criadores, instaurando mais do que uma moral voltada para a conservação, uma moral da aspiração, realizando "em nosso planeta refratário, a função essencial do universo", nas palavras que fecham o livro. Os homens capazes do esforço imenso exigido para que essa condição seja alcançada, chamados de místicos pelo nosso autor, são personalidades que se inscrevem na história ao empenhar o famoso salto de uma moralidade da pressão social para uma moralidade da aspiração, indo de uma só vez do instituído para a instauração de uma moral universal. Nesses indivíduos há um dilatamento de espírito; um transbordamento de uma alma que se volta para o seu sentido temporal e contínuo, superando o invólucro social - e também espacial - e particular em que a inteligência os teria encerrado, para apreender essa realidade movente que os habita - "o eu profundo" - ao mesmo tempo em que os transcende, permitindo que eles se coincidam com realidades e existências outras.

No interior dessa moral da aspiração (caracterizada, como descreve o autor, por um chamado à ação solidária, mais do que por uma resistência à ação egoísta, como é o caso da moral da pressão), a indiferença positiva ou o princípio da igual consideração de interesses e qualquer consideração absoluta de valor, direito ou justiça, serão já emanações dessa experiência da abertura bergsonista. Experiência que escapa aos contornos da inteligência e do caráter espacial no qual esta opera, remetendo-nos à realidade temporal. Afinemos nossos instrumentos para essa nova matéria do conhecimento e perceberemos que ali onde víamos fechamento e individualidade há comunhão e laços indissociáveis em um todo contínuo; que ali onde nosso 
materialismo postulava a realidade individual dos seres dispostos e separados no espaço, um espiritualismo (bastante distinto do clássico) preencheria o suposto vazio entre os seres, desvendando a sua continuidade, o que operaria uma abertura do homem para a totalidade dos seres, para um tipo de fraternidade que jamais poderia ser contemplada pelas teorias tradicionais do direito.

Segundo Bergson, o direito tradicional, enquanto obra da inteligência e, portanto - visto que esta "recomendaria antes o egoísmo" - sendo primeiro a expressão natural do autorreferenciamento constitutivo da espécie, interpreta o conceito de justiça primeiro com a noção quantitativa, ilustrada pela balança. A recomendação aqui é a lei do talião - à qual talvez estivéssemos determinados, caso não houvesse ao redor de nossa inteligência uma franja que nos lança para além do mundo representado pelo intelecto, a saber, a intuição, pela qual coincidimos com a temporalidade constitutiva do real. Assim, graças a essa franja que se perde na noite, usando a imagem bergsoniana, há entre nós seres capazes de se elevarem acima da condição puramente egoística - e mesmo social - e demandarem a radical inclusão da alteridade radical, merecedora de consideração moral, de maneira absoluta, não relativa à utilidade pessoal, pois (o místico seria aquele capaz de amar sem interesse, tudo o que existe e vive mesmo que seres vivos não mais existissem no planeta). Essa nova relação com a vida e com os seres, cuja força transcende os tempos e toca aqueles que se não são capazes do mesmo esforço, - e que não são menos portadores de uma potencial abertura - acaba por forçar o alargamento das primeiras instituições, criadas para a proteção de indivíduos particulares. Para dilatarmos a moral que a natureza nos dá a título de instinto social com um conteúdo de alteridade absoluto e assim abrir o escopo naturalmente fechado da nossa natureza social (termo com que Bergson designa uma ordem de contornos fixos que exclui os que não são por ela contemplados), teremos que volver à outra direção do movimento da vida, a que tende não para o espaço, a materialidade em seus contornos fechados, mas a que tende para o criação contínua, ou a temporalidade real, a duração. Daqui, a igualdade apareceria como um sentimento profundo, uma experiência concretamente sentida e prévia aos quais se juntam razões para descrevê-los, e não como uma verdade evidente conhecida pela razão pura, que deva justificar e criar tal sentimento. 
Abordamos sinteticamente a crítica bergsoniana à constituição do pensamento inteligente e racional, esboçada no decurso da obra do autor, e segundo a qual a filosofia grega teria sido uma espécie de desenvolvimento natural de uma tendência a abordar os objetos do conhecimento (todos eles) a partir de uma razão que transporta para realidades imateriais intensivas as mesmas ferramentas intelectuais de recorte e medida usadas na abordagem dos objetos extensos. 0 pensamento tradicional moderno sobre a moral descenderia da filosofia grega de um ponto de vista ontogenético, na medida em que se apresenta como desdobramento natural da inteligência, que se dispõe a conhecer o mundo em sua totalidade, aplicando a toda a realidade as mesmas ferramentas adequadas para conhecer apenas uma parte dela, aquela que se materializa e se estabiliza aos olhos da inteligência. Corrigido o erro genético e adicionadas a nova matéria (temporal) para o conhecimento, bem como as novas ferramentas de abordá-la (intuitivas), a moral se desvendará como algo mais que mera contenção ao egoísmo necessária à manutenção da vida em sociedade. Ela se revelará como uma criação impulsionada pelo movimento vital e criador, operado pelos homens que logram saltar para além do universo desenhado pelas representações intelectuais e espaciais, que constituem o círculo em que eles estão condenados a girar. A despeito da crítica que a obra bergsoniana traz à ideia de moral, uma espécie de "progresso" moral ressurgirá no rastro das demandas dos místicos. Ainda que a sociedade como um todo esteja fadada ao fechamento - pelo que não pode se constituir em sociedade feita só místicos, ou deuses -, poderemos pensar em graus ou composições distintas de fechamentos, uns mais amigáveis à solidariedade do que outros, incorporando, por exemplo, um grupo quantitativamente maior e com mais diversidade em suas fórmulas de convivência e instituições, conforme sejam mais aderentes ou não à busca da institucionalização da obra dos místicos; conforme estejam estas fórmulas mais dispostas a imitá-los, portanto.

\section{Conclusão}

Falar de direito mecanicista - aquele que se toma por obra da pura razão - é falar da forma com que somos levados, por natureza, a especular sobre o Direito. Essa tendência ao fechamento e à imobilização do fluxo do real, operada pela inteligência ao abordar o movimento 
com as suas categorias estáticas, parece levar a uma metafísica dogmática, que toma o indivíduo (de fato e direito) como única realidade relevante para a moral (mesmo quando fala em interesse da sociedade), e ainda assim quer afirmar o imperativo categórico que diz respeito aos interesses de um outro, alheio. 0 fato social se cobrirá de mistério e o momento do contrato social, sempre imaginado como se pudesse nunca ter sido - uma vez que o egoísmo entendido sem o contrapeso de um instinto social, que operará automaticamente e independente da vontade humana, destruiria toda a possibilidade de vida em conjunto. De todo modo, se a sociedade é um fato,dirão os liberais, seria por conta de algum benefício que a união traria a cada indivíduo particular. Proceder à abertura da moral significa lançar outras bases teóricas para compreendê-la em totalidade. Partamos, com Bergso, da sociedade enquanto quista pela natureza. Dado o perigo que a inteligência - a despeito dos ganhos que traz - representa, ao nos engajar no egoísmo, há um tipo de moralidade que nos é natural, diretamente quista pela natureza: trata-se da moral da pressão, instinto social em nós que garante a viabilidade da espécie - a qual, aliás, teria sido "tudo o que a natureza pode ter feito por nós". O problema é que esse instinto moral, digamos assim, encontra um limite natural, o grupo e a administração dos egoísmos particulares no interior dessa associação. Há, entretanto, possibilidade de refazermos o esforço que dobra essa tendência e nos colocarmos em outro registro moral, ao entrarmos em contato com essa outra substância do real, que nos constitui junto à matéria: o processo temporal que nos permite coincidir com o movimento da vida, para além das formas estáticas instauradas pelo mundo humano (eis o "salto" que o místico realiza). A mística retoma o nosso contato possível com o objeto da metafísica, e munidos de uma ética ontológica, podemos dar solução aos pseudoproblemas com que tem se enredado o pensamento clássico sobre moral.

Dizer "do direito mecanicista à mística" é o mesmo que dizer de uma concepção individualista da ética para uma concepção solidária e aberta, na qual já não afirmamos a apartação (de direito) entre os seres, mas uma comunhão radical entre todos eles. Uma moral ancorada na metafísica bergsoniana - e no modo pelo qual ele próprio pensa a moralidade aberta em sua última obra - permite vislumbrar um direito que incorpore, ainda que sempre em processo e não de modo definitivo, a legitimidade das alteridades todas. Mais precisamente, dizer de um 
direito e de uma lei que estão entre a mecânica e a mística é dizer, com Bergson, que há idealmente duas direções do movimento vital, as quais ele teria abstraído do misto que se nos oferece à experiência, em sua dualidade natural. É dizer que as criações humanas - em geral e aquelas associadas à ordem moral, em particular -, podem se atualizar preponderantemente em uma ou outra das direções. Mas é também aludir à maior facilidade que temos para tomar o primeiro caminho; da tendência natural de tudo o que é por decair no caminho da matéria e do espaço, tendência reforçada pelas formas com que materializamos as criações do espírito. É dizer, por fim, de um esforço antinatural (mas interior à vida e permitido por ela) para tomar o outro caminho e alargar sucessivamente as formas legais e as concepções sobre o Direito. Um direito que não libertará o homem da clausura em que ele se encerra, mas que será em alguma medida inebriado por aqueles que lograram saltar para além do círculo, mobilizados pela intuição e por uma emoção criadora - portanto temporal - que faz deles criadores e inventores de uma outra moral ou de uma nova ética.

Procuramos formular o problema da alteridade em termos de uma distinção radical entre dois pontos de partida para a consideração moral: ou tomamos o direito natural tão somente como ferramenta de manutenção da coesão social e garantia da viabilidade e reprodução da espécie, que endereça ao indivíduo inteligente o seu conteúdo de modo a fundar a célebre "resistência à resistência" (e sobre a capacidade de dissuasão que as punições representam os utilitaristas tem tanto a nos dizer), ou o consideramos também como ferramenta pela qual podemos realizar não apenas a reprodução, mas o progresso da humanidade.

A resistência à extensão e manutenção dos direitos das várias minorias (animais não humanos inclusos) aparenta, desse segundo ponto de vista, fundar-se nessa incapacidade de abrir-se para uma alteridade universal, a qual é sequer pensada como verdadeiramente possível se nos limitamos à primeira interpretação do direito. Ao considerarmos o ponto de vista bergsonista, ser-nos-á aberta a perspectiva de incluir algum “outro" alheio ao grupo no interior do qual a coesão e reprodução da vida social de um indivíduo particular opera, alargando o seu círculo de consideração moral. Operação que, a despeito do seu caráter ainda intelectual e procedente por abstração, parece requerer uma vontade distinta dela e, como é da natureza dessa 
vontade, um desligamento da atenção à vida ou um arrefecimento da tendência espacial-fabricadora. As teorias da moral clássica, hegemônicas, não conseguem dar resposta suficiente, tampouco são capazes de oferecer programa satisfatório para que atinjamos eficácia nas recomendações que por vezes logra alcançar intelectualmente - sempre, ademais, passíveis de serem relativizadas com alguma coerência, conforme tentamos mostrar. Problemas como os direitos animais; todos os tipos de preconceitos e exclusão de grupos humanos (xenofobia; homofobia; racismo; sexismo) poderão ser abordados a partir da nova perspectiva, segundo a qual não se trata mais de mera operação linguística, aquela segundo a qual separamos um grupo, o nosso, dos demais (discriminar, no sentido próprio da palavra), e sim um modo de vida que não poderá ser mudado (visto que é antes atingido) pelo puro exercício da razão, ou pela mera justaposição de argumentos, senão pela iniciação em um novo modo de vida.

\section{Bibliografia}

ARISTÓTELES. Ética a Nicômaco; Os Pensadores. São Paulo, Abril Cultural, 1984.

BENTHAM, Jeremy. Uma introdução aos princípios da moral e da legislação em Os Pensadores. São Paulo: Abril Cultural, 1984.

BERGSON, Henri. As Duas Fontes da Moral e da Religião. RJ: Zahar Editores, 1978.

A Energia Espiritual. São Paulo: Martins Fontes, 2009.

. A Evolução Criadora. Rio de Janeiro: Zahar Editores, 1979.

. Aulas de Psicologia e de metafísica. São Paulo: Martins Fontes, 2014.

. Ensaio sobre os dados imediatos da consciência. Lisboa: Edições 70, 2008.

Matéria e Memória. São Paulo: Martins Fontes, 1999.

. O pensamento e o movente: ensaios e conferências. São Paulo: M. F., 2006.

DELEUZE, G. Bergsonismo. São Paulo: Editora 34, 1999.

CAPPELLO, Maria Adriana C. Democracia em as duas fontes da moral e da religião: Resistência e Aspiração In TransFormAção. Marília, v. 40, n. 2, Abr./Jun., 2017.

FREUD, S. O mal-estal na civilização. São Paulo: Companhia das Letras, 2012.

GALVÃO, Pedro. Utilitarismo, de John Stuart Mill. Porto: Porto Editora, 2005.

HOBBES, T. Leviatã ou Matéria, forma e poder de um Estado eclesiástico e civil. Tradução de João Paulo Monteiro e Maria Beatriz Nizza da Silva, col. Os Pensadores.

KANT, I. Crítica da razão prática. São Paulo: Editora WMF Martins Fontes, 2016. 
LANDIM, M. L. P. F. Ética e natureza no pensamento de Bergson. RJ: UAPÊ, 2001.

LAPOUJADE, David. Potências do tempo. São Paulo: N-1 edições, 2013.

LEFEBVRE, A. Humans rights as a way of life: on Bergson's political philosophy. California: Stanford University Press, 2013.

LEFEBVRE, A. e WHITE, M. Bergson, politics and religion. Duke University, 2012.

LEFORT, C. A Invenção Democrática. São Paulo: Brasiliense, 1983.

. As Formas da História. São Paulo: Brasiliense, 1990.

PAIVA, Rita. Um desvio do sentido: o primitivo e o civilizado em Bergson In doispontos:, Curitiba, São Carlos, volume 14, número 2, p. 139-160, dezembro de 2017.

. A moral e a política sob a égide da natureza ou nos antípodas do universal In Dossiê Bergson, Dissertatio - Volume Suplementar 4. UFPel, 2016.

STULL, Miguel Ruiz. Bergson y el acontecimiento. El caso de la guerra In TransFormAção. Marília, v. 40, n. 2, p. 163-174, Abr./Jun., 2017.

RACHELS, J. Os elementos da filosofia moral. Barueri, SP: Manole, 2006.

SINGER, Peter. Libertação Animal. Porto Alegre: Lugano Editora, 2004.

WORMS, F. Bergson ou os dois sentidos da vida. São Paulo: Editora UNIFESP, 2011.

Recebido em: 01/07/2020

Aprovado em: 06/01/2021

\section{João Batista Magalhães Prates}

Graduado e mestrando em Filosofia pela UNIFESP, bolsista CAPES-DS. 